\title{
Flt3 ligand promotes myeloid dendritic cell differentiation of human hematopoietic progenitor cells: Possible application for cancer immunotherapy
}

\author{
SACHIO HARADA ${ }^{1,2}$, TAKAFUMI KIMURA ${ }^{1}$, HIROSHI FUJIKI ${ }^{2}$, HITOSHI NAKAGAWA ${ }^{3}$, \\ YUJI UEDA ${ }^{2}$, TSUYOSHI ITOH ${ }^{2}$, HISAKAZU YAMAGISHI ${ }^{2}$ and YOSHIAKI SONODA ${ }^{1}$ \\ ${ }^{1}$ Department of Stem Cell Biology and Regenerative Medicine, Graduate School of Medical Science, \\ Kansai Medical University, Osaka; ${ }^{2}$ Department of Surgery and Oncology of Digestive System, \\ Graduate School of Medical Science, Kyoto Prefectural University of Medicine; \\ ${ }^{3}$ Department of Hematology, Kyoto First Red Cross Hospital, Kyoto, Japan
}

Received January 15, 2007; Accepted February 23, 2007

\begin{abstract}
Current in vitro culture systems allow the generation of human dendritic progenitor cells (CFU-DCs). The aim of this study was to assess the effect of Flt3 ligand (FL) on the proliferation of human peripheral blood-derived myeloid CFU-DCs and their differentiation into more committed precursor cells (pDCs) using in vitro culture systems. Immunomagnetically separated $\mathrm{CD} 34^{+}$cells were cultured in serum-free, as well as in serum-containing, liquid suspension cultures to investigate the expansion and/or proliferation/ differentiation of CFU-DCs, pDCs, and more mature dendritic cells (DCs). FACS-sorted CD $34^{+}{ }^{\mathrm{Flt}} 3^{+/-}$cells were cultured in methylcellulose to assay hematopoietic progenitors, including CFU-DCs. In the clonal cell culture supplemented with granulocyte/macrophage (GM) colony-stimulating factor (CSF), interleukin-4, and tumor necrosis factor $\alpha$, the frequency of CFU-DCs was significantly higher in the CD34+Flt $3^{+}$ fraction than in the $\mathrm{CD} 34^{+} \mathrm{Flt} 3^{-}$population, thus suggesting functional Flt3 expression on CFU-DCs. Serum-free suspension culture of $\mathrm{CD}_{3} 4^{+}$cells revealed the potent effect of FL on the expansion of CFU-DCs in synergy with GM-CSF and thrombopoietin (TPO). In addition, FL strongly induced the maturation of CFU-DCs into functional CD1a $\mathrm{a}^{+} \mathrm{pDCs}$ in serum-containing liquid suspension culture. Moreover, these FL-generated pDCs showed remarkable potential to differentiate into mature DCs with surface CD83/CD86 expression, which induced a distinct allogeneic T-cell response. These
\end{abstract}

Correspondence to: Dr Yoshiaki Sonoda, Department of Stem Cell Biology and Regenerative Medicine, Graduate School of Medical Science, Kansai Medical University, Moriguchi, Osaka 570-8506, Japan

E-mail: sonoda@takii.kmu.ac.jp

Key words: Flt3 ligand, hematopoietic progenitor cell, dendritic cell, CD $34^{+}$cell, cancer immunotherapy results clearly demonstrate that FL supports not only the proliferation of early hematopoietic progenitor cells, but also the maturation process of committed precursor cells along with the DC-lineage differentiation. Therefore, it is possible to develop a more efficient DC-based cancer immunotherapy using this specific cytokine combination, GM-CSF+TPO+FL in vitro in the near future.

\section{Introduction}

Hematopoietic stem cells (HSCs) are known to have a robust capacity of multilineage differentiation, which is mainly regulated by the extrinsic environment, including cytokines or adhesion molecules expressed on neighboring cells $(1,2)$. However, targeted deletion or overexpression of lineagespecific transcription factors leads to recovery of the differentiation potential into alternative lineages. For instance, pre-B cells in Pax-5-null mice can differentiate into mature $\mathrm{T}$ lymphoid and myeloid cells despite their defective potential for B lymphoid maturation (3). In addition, with the enforced expression of a myeloid-restricted cytokine receptor $(\mathrm{R})$, granulocyte/macrophage colony-stimulating factor-R (GMCSF-R) on hematopoietic progenitors (HPCs) results in a biased generation of myeloid cells (4). Lineage restriction in HSC/HPC differentiation may thus be controlled not only stochastically by intrinsic factors, but also instructively by expression levels of transcription factors or cytokine receptors.

Dendritic cells (DCs) are known as one of the most important players in the regulation of innate and adaptive immunity (5-8). They are recruited from the HSC pool like cells in other hematopoietic lineages (9-13). In mice, several DC compartments have been identified according to their immunophenotypes. It has also been reported that DCs are produced only from HPCs which express Flt3 on their surfaces $(14,15)$.

While Flt3 is a receptor tyrosine kinase showing some structural homology to c-kit and c-fms (16), Flt3 ligand (FL) has the most potent activity for DC differentiation in mouse 
bone marrow cells in vitro when used as a single cytokine $(17,18)$. In human hematopoiesis, FL acts on the proliferation and differentiation of myeloid as well as erythroid stem/ progenitor cells in vitro in synergy with other early-acting cytokines, such as stem cell factor (SCF, c-kit ligand) and thrombopoietin (TPO) (19-23). A combination of these three factors is also well known to support the in vitro expansion of DC progenitors $(24,25)$, although the mechanisms of the factor-specific functions, as well as their synergistic actions, still remain unclear. We herein show the precise role of FL on the proliferation and differentiation of human CD34+ HPCs into functional DC precursors (pDCs) using in vitro culture systems. Our results indicate that FL is more reliable than SCF in instructing human DC progenitors expressing Flt3 to generate functional progenies.

\section{Materials and methods}

Recombinant factors. Purified bacterially-derived recombinant human (rh) granulocyte $(\mathrm{G})$ colony-stimulating factor (CSF), and thrombopoietin (TPO), as well as purified Chinese hamster ovary cell-derived rh erythropoietin (Epo), were kindly supplied by Kirin Brewery Co., Ltd. (Tokyo, Japan). Purified rh IL-4 was a generous gift from Ono Pharmaceutical Co., Ltd. (Osaka, Japan). Yeast-derived rh Flt3 ligand (FL) was provided by Immunex Research and Development Corp. (Seattle, WA, USA). Purified rh interleukin (IL)-3, granulocyte/macrophage (GM)-CSF, stem cell factor (SCF), and tumor necrosis factor $\alpha$ $(\mathrm{TNF} \alpha)$ were all purchased from R\&D systems (Minneapolis, $\mathrm{MN}, \mathrm{USA})$.

Cell preparation. After informed consent was obtained, peripheral blood mononuclear cells (PBMNCs) were collected from patients with non-Hodgkin's lymphoma in first complete remission by leukapheresis using Fenwall CS-3000 Plus (Fenwall Laboratories, Inc., Deerfild, IL, USA), and were stored in liquid nitrogen until use in the present study, according to a method previously reported (26-28). After rapid thawing, cells were incubated on plastic dishes containing $\alpha$ MEM (Invitrogen Corp., Carlsbad, CA, USA) supplemented with $10 \%$ fetal calf serum (FCS, Hyclone Laboratories, Logan, UT, USA) overnight at $37^{\circ} \mathrm{C}$ in a fully humidified atmosphere flushed with $5 \% \mathrm{CO}_{2}$. The mononuclear non-adherent cell (MNNAC) fraction was then recovered for subsequent immunomagnetic isolation or flow cytometric cell sorting.

Immunomagnetic isolation and flow cytometric cell sorting. The above-mentioned MNNACs were further enriched for CD34+ cells using a MACS immunomagnetic microbeads system (Miltenyi Biotec, Bergisch Gladbach, Germany) or for lineagedepleted ( Lin $^{-}$) cells using a StemSep device (Stem Cell Technologies, Vancouver, BC, Canada), according to the manufacturer's instructions, and as described previously $(29,30)$. The purity of $\mathrm{CD}_{3} 4^{+}$cells in these isolated cell fractions was confirmed by flow cytometry to be constantly more than $95 \%$. The isolated cells were subsequently processed for liquid suspension culture or cell sorting as described below.

For flow cytometric cell sorting, Lin $^{-}$cells were incubated for $30 \mathrm{~min}$ at room temperature with purified anti-human Flt3 $\mathrm{mAb}$ (clone M22, kindly provided by Immunex Corp.), which had been biotinylated as described previously $(23,26,28)$, and followed by staining with fluorescein isothiocyanate (FITC)-conjugated HPCA-2 [CD34 mAb, Becton Dickinson Immunocytometry Systems (BD), San Jose, CA, USA] and streptoavidin (SA)-phycoerythrin (PE) (BD) for $30 \mathrm{~min}$ on ice. Negative controls included unstained cells and cells stained only with FITC-conjugated isotype $\operatorname{IgG}_{1}$ (BD) and SA-PE. Cell sorting was performed using a FACSVantage (BD), as previously reported (28-30). Sorting windows were established for $\mathrm{CD}^{2} 4^{+} \mathrm{Flt}^{+}{ }^{+}$or $\mathrm{CD} 34^{+} \mathrm{Flt} 3{ }^{-}$cells as shown in Fig. 1a and b. Data acquisition was performed using CELLQuest software (BD). The phenotypic purity of the sorted cells consistently exceeded $98 \%$.

Clonal cell culture. $\mathrm{CD} 34^{+} \mathrm{Flt} 3^{+}$or $\mathrm{CD} 34^{+} \mathrm{Flt} 3-$ cells were cultured in 35-mm Lux suspension culture dishes (no. 171099, Nunc Inc., Naperville, IL, USA), as reported previously (26-30). Briefly, $1 \mathrm{ml}$ of culture contained 200 sorted cells, $1.2 \%$ methylcellulose (Shinetsu Chemicals, Tokyo, Japan), $30 \%$ FCS, $1 \%$ bovine serum albumin (fraction V, Sigma Chemical Co., St. Louis, MO, USA), $5 \times 10^{-5} \mathrm{~mol} / 1$ 2-mercaptoethanol (Sigma), and $5 \mathrm{CSFs}(20 \mathrm{ng} / \mathrm{ml} \mathrm{SCF}, 10 \mathrm{ng} / \mathrm{ml}$ IL-3, $10 \mathrm{ng} / \mathrm{ml}$ GM-CSF, $20 \mathrm{ng} / \mathrm{ml}$ G-CSF, and $2 \mathrm{U} / \mathrm{ml}$ Epo). Dishes were incubated at $37^{\circ} \mathrm{C}$ in a fully humidified atmosphere flushed with a combination of $5 \% \mathrm{CO}_{2}, 5 \% \mathrm{O}_{2}$, and $90 \% \mathrm{~N}_{2}$. On days 12-14 of incubation, colonies were scored according to their typical morphological features using an inverted microscope, as reported (26-30). Colony types identified in situ were granulocyte/macrophage (CFU-GM), erythroid (BFU-E), and erythrocyte-containing mixed (CFU-Mix) colonies.

To examine dendritic colony (CFU-DC) formation, 500 sorted $\mathrm{CD}_{3} 4^{+} \mathrm{Flt} 3^{+}$or - cells or cells recovered from serumcontaining liquid cultures described below were cultured in the presence of $20 \mathrm{ng} / \mathrm{ml} \mathrm{GM-CSF}, 100 \mathrm{U} / \mathrm{ml} \mathrm{IL-4}$, and $100 \mathrm{U} / \mathrm{ml}$ TNF $\alpha$. On days 12-14 of incubation, DC colonies were scored, as described previously (31).

Liquid suspension culture. A total of $5 \times 10^{3}$ immunomagnetically isolated $\mathrm{CD}_{34}{ }^{+}$or Lin ${ }^{-}$cells were cultured in $35-\mathrm{mm}$ Lux suspension dishes containing $1 \mathrm{ml}$ of StemPro-34 medium (Invitrogen) supplemented with the designated combination of CSFs, which included $20 \mathrm{ng} / \mathrm{ml} \mathrm{GM-CSF}, 100 \mathrm{ng} / \mathrm{ml} \mathrm{TPO}$, $20 \mathrm{ng} / \mathrm{ml} \mathrm{SCF}$, and $20 \mathrm{ng} / \mathrm{ml} \mathrm{FL}$. Dishes were incubated at $37^{\circ} \mathrm{C}$ in a fully humidified chamber flushed with a combination of $5 \% \mathrm{CO}_{2}, 5 \% \mathrm{O}_{2}$, and $90 \% \mathrm{~N}_{2}$. On day 7 , half of the culture medium was exchanged with freshly prepared medium. After 14 days of incubation, the number of viable cells in each dish was counted and replaced into clonal cell cultures.

In addition, $\mathrm{CD}_{34}{ }^{+}$or Lin- $^{-}$cells were incubated in RPMI 1640 (Invitrogen) supplemented with $10 \%$ FCS and the designated factors. After 14 days of incubation, these cells were transferred into DC maturation culture medium containing $10 \%$ FCS/RPMI supplemented with GM-CSF, IL-4, and $\mathrm{TNF} \alpha$. On day 7, 14, and 21 of incubation, a portion of cultured cells was processed for flow cytometry, as described below.

Flow cytometry. Immunomagnetically isolated cells or cells harvested from suspension cultures were stained with FITCconjugated mAbs against human CD11c (eBioscience, San 

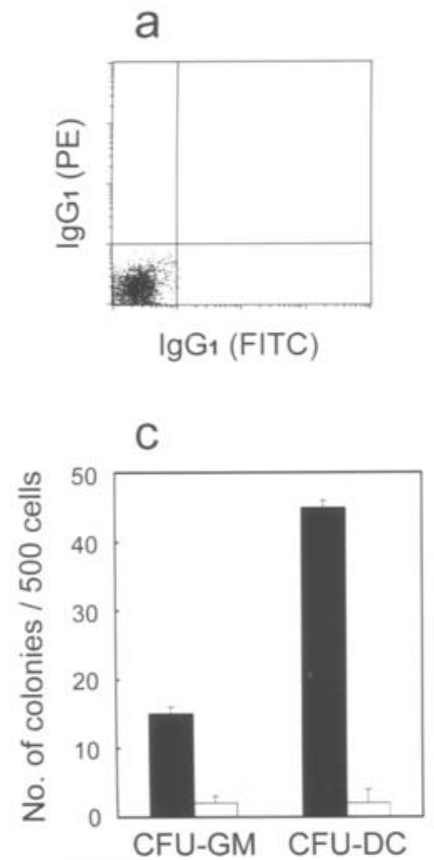

b

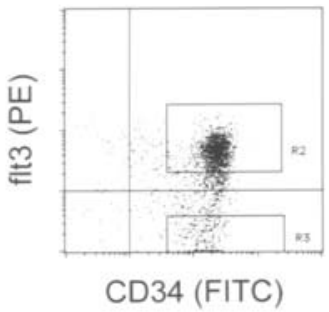

d

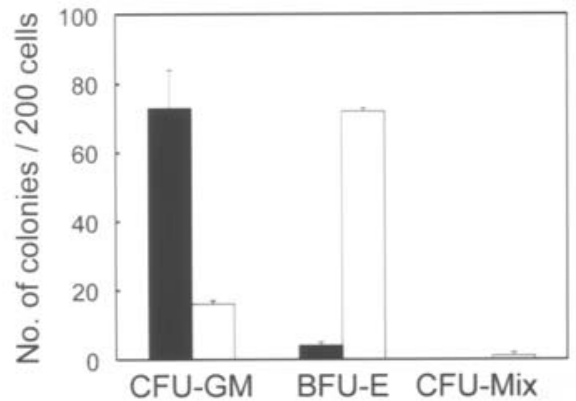

Figure 1. Characterization of PB-derived Lin-CD34+Flt $3^{+/-}$cells and their colony-forming capacity. The R1 gate was set on the lymphocyte window on the FSC/SSC profile of immunomagnetically isolated Lin- cells (not shown). (a) Isotype control. (b) Cells in the R1 gate were further enriched by cell sorting as $\mathrm{CD}^{2} 4^{+} \mathrm{Flt} 3^{+}(\mathrm{R} 2)$ and $\mathrm{CD}^{+} 4^{+} \mathrm{Flt3} 3^{-}(\mathrm{R} 3)$ cells, respectively. The sorted cells were incubated in methylcellulose culture. (c) A total of 500 sorted cells were incubated with GM-CSF, IL-4 and TNF $\alpha$. (d) Two hundred sorted cells were cultured in the presence of SCF, IL-3, GM-CSF, G-CSF and Epo. The number of GM, erythroid, mixed, and DC colonies were directly counted in situ on days 12-14 of incubation. The data represent the mean \pm SEM from three independent experiments. Closed and open bars show the number of colonies generated from CD $34^{+} \mathrm{Flt}^{+}{ }^{+}$and $\mathrm{CD} 34^{+} \mathrm{Flt} 3^{-}$cells, respectively.

Diego, CA, USA), CD14 (BD), CD54 (Beckman Coulter, Fullerton, CA, USA), CD80 and CD86 (both from Caltag Laboratories, Burlingame, CA, USA), PE-conjugated antihuman CD1a (Coulter), CD83 (Caltag), and HLA-DR (BD) mAbs. Dead cells were gated out by simultaneous staining with 7-AAD (Coulter). Data acquisition and analysis were performed using CELLQuest software on a FACSCalibur (BD).

Mixed lymphocyte reaction (MLR). The antigen-presenting capacities of DCs were assessed by MLR, as previously described (25), with some modifications. In brief, allogeneic T-cells were isolated as responders using nylon fiber columns (Wako, Osaka, Japan). A total of $1 \times 10^{5}$ cells were incubated in 96-well microtiter plates (Nunc) with the designated numbers of $\gamma$-irradiated (250 cGy) DCs generated from CD34+ cells in the above-mentioned serial liquid suspension culture for 21 days. After 5 days of incubation, cultures were pulsed with $1.0 \mu \mathrm{Ci} /$ well $\left[{ }^{3} \mathrm{H}\right]$-thymidine for $8-12 \mathrm{~h}$ to measure the $\mathrm{T}$-cell proliferation, expressed as $\left[{ }^{3} \mathrm{H}\right]$-thymidine incorporation by scintillation counting.

Statistical analysis. The significance of differences was determined by the paired t-test.

\section{Results}

Functional expression of Flt3 on human DC progenitors. We first investigated the Flt3 receptor expression on $\mathrm{PB}$-derived $\mathrm{CD} 4^{+}$cells. As shown in Fig. 1a and b, 82.4 $\pm 3.0 \%(\mathrm{n}=6)$ of $\mathrm{CD} 34^{+}$cells expressed Flt3 on their surfaces. We then assessed the colony-forming capacity of sorted $\mathrm{CD} 34^{+} \mathrm{F} 1 \mathrm{t} 3^{+}$ and $\mathrm{CD} 34^{+}{ }^{+}{ }^{2} 3{ }^{-}$cells. Data obtained from the three independent clonal cell culture experiments are presented in Fig. 1c and d. Of note was that the number of myeloid DC colonies supported by GM-CSF+IL-4+TNF $\alpha(\mathrm{G} 4 \mathrm{TN})$ was strikingly higher in the culture of $\mathrm{CD} 34^{+} \mathrm{Flt} 3^{+}$cells compared to the $\mathrm{CD} 34^{+} \mathrm{Flt} 3$ cell fraction $(\mathrm{P}<0.01)$. In addition, $\mathrm{CD} 34^{+} \mathrm{Flt} 3^{+}$cells generated a significantly $(\mathrm{P}<0.01)$ higher number of $\mathrm{CFU}-\mathrm{GM}$-derived colonies, while most colonies in cultures of CD34+Flt3- cells were derived from BFU-E or CFU-Mix $(\mathrm{P}<0.01)$. These results indicated the possibility that Flt3 is expressed as a functional molecule on CFU-DC as well as CFU-GM.

Ex vivo expansion of DC progenitors by $F L$. It has been well documented that GM-CSF has the most potent effect on the DC-lineage differentiation of hematopoietic progenitors (HPCs) (11), while TPO, SCF, and FL have been shown to synergistically support the efficient expansion of early hematopoietic stem/progenitor cells in vitro $(21,24,25)$. A combination of these early-acting CSFs also strongly enhances the proliferation of $\mathrm{CD} \mathrm{a}^{+}$precursor DCs (pDCs) $(24,25)$. On the other hand, c-kit and Flt3, which are activated with their respective ligands, SCF and FL, have been shown to have similar but specific tyrosine kinase activities (32). We therefore aimed to evaluate and compare the effect of FL and SCF on the proliferation of DC progenitors.

Representative data from three independent serum-free suspension cultures of CD34+ cells are shown in Fig. 2 . Although the total cell number at day 14 significantly $(\mathrm{P}<0.05)$ 


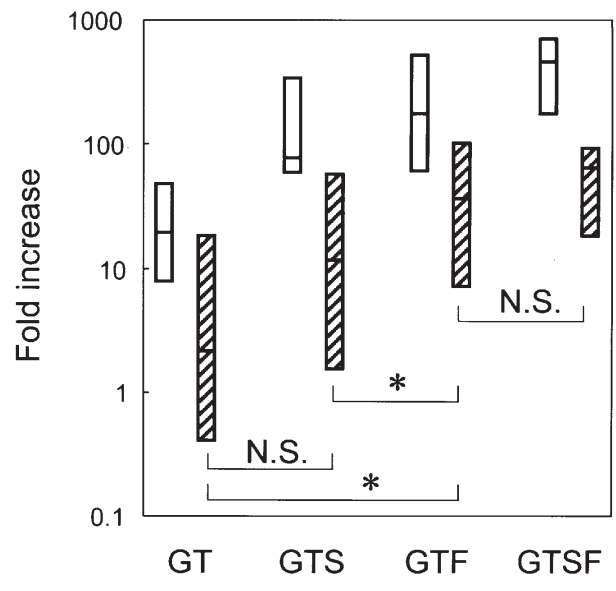

Figure 2. Effects of various cytokine combinations on ex vivo expansion of DC progenitors. The data represent the fold increase of cultured cells at day 14 of incubation. Open and striped columns show the values from total cell numbers and CFU-DCs, respectively. Horizontal bars represent the respective medians. NS, not significant. ${ }^{*} \mathrm{P}<0.05$.

increased in the cultures containing GM-CSF+TPO+SCF (GTS) or GM-CSF+TPO+FL (GTF), in comparison to GM-CSF+TPO (GT), no significant difference was observed between GTS and GTF. The proliferation of DC progenitors (CFU-DCs) was more strongly supported by GTF than by GTS $(\mathrm{P}<0.05)$, while a combination of four cytokines (GTSF) did not enhance CFU-DC proliferation more profoundly. These results suggest that, in comparison to SCF, FL acts more specifically and potently on the proliferation of myeloid DC progenitors expressing its receptor Flt3, as well as on other lineage-committed progenitors.
Differentiation of $\mathrm{CD}^{3} 4^{+}$cells to DC precursors ( $p D C s$ ) by $F L$. We assessed the serial effects of FL on the DC-lineage differentiation of CD34+ $\mathrm{HPCs}$. Purified CD34+ cells were cultured in serum-containing media supplemented with GTS, GTF or GTSF. After 14 days of culture with GTS, $10 \%$ of cells weakly expressed both $\mathrm{CD} 11 \mathrm{c}$ and CD1a antigens (Fig. 3b), which are specific for pDCs. Interestingly, $>50 \%$ of cells expressed these antigens after the same period of culture with GTF, whose fluorescence intensities were significantly higher than those with GTS (Fig. 3e). On the other hand, a combination of GTSF did not increase these DC-markers' expression as compared to GTF (Fig. 3h). Cells harvested from cultures supplemented with GTS, GTF and GTSF were further incubated with G4TN for another 7 days. As shown in Fig. 3c, f and i, the expression levels of CD11c and CD1a in these cells on day 21 were comparable despite the initial cytokine combination. These results indicate that FL can accelerate the differentiation of $\mathrm{CD} 34^{+}$HPCs to pDCs.

As with CD11c expression, a combination of GTF induced the differentiation of $\mathrm{CD} 34^{+}$cells to $\mathrm{CD} 14^{+} \mathrm{CD} 1 \mathrm{a}^{+} \mathrm{pDCs}$ more rapidly than GTS or GTSF (Fig. 4b, e and h). As clearly seen in Fig. 4-c, f and i, CD14 ${ }^{+} \mathrm{CD} 1 \mathrm{a}^{+}$pDCs turned to CD14- fully mature DCs after stimulation with G4TN for another 7 days.

These findings provide evidence that $\mathrm{FL}$ acts on $\mathrm{CD} 34^{+} \mathrm{Flt} 3^{+}$ DC progenitor cells and accelerates their differentiation to mature DCs in the presence of GM-CSF and TPO. The combination of four factors (GTSF), however, did not show any additive effects as compared to GTF.

Induction of functional DCs by FL. As shown in Figs. 3 and 4 , the cytokine combination of G4TN induced DC-lineage differentiation of cultured $\mathrm{CD} 34^{+}$cells to $\mathrm{CD} 11 \mathrm{c}^{+} \mathrm{CD} 14-\mathrm{CD} 1 \mathrm{a}^{+}$ $\underline{\text { GTS }}$
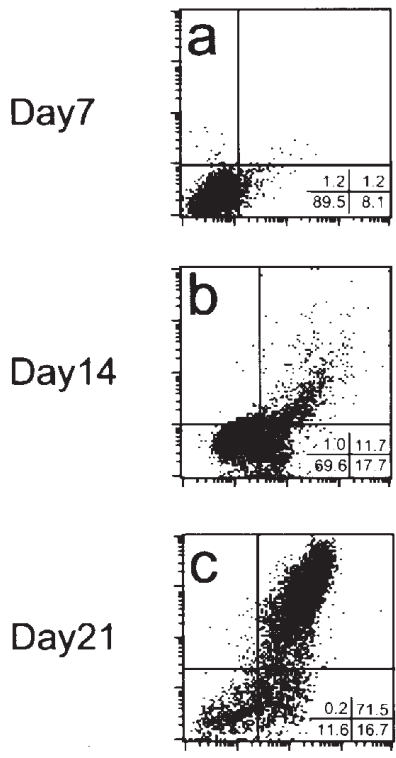

$\underline{\text { GTF }}$
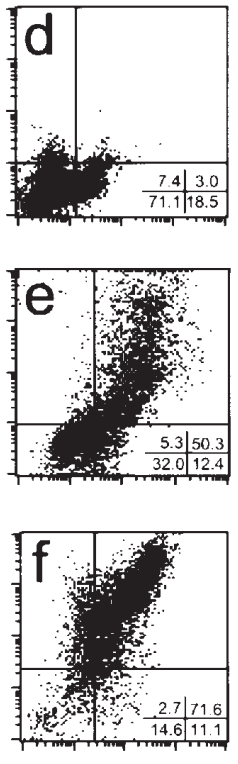

CD11c (FITC)
GTSF
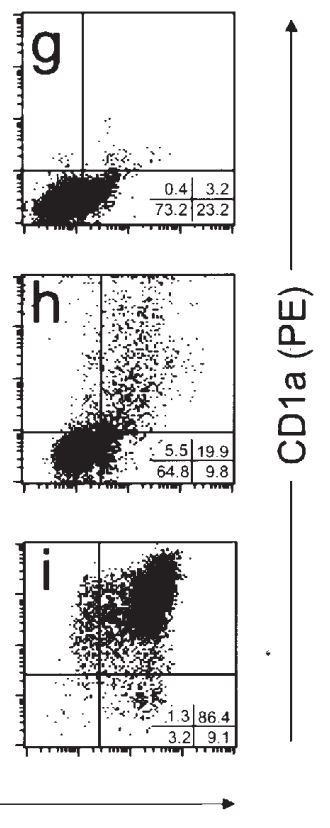

Figure 3. Differentiation of CD34 $4^{+}$cells to CD11 $\mathrm{c}^{+} \mathrm{CD} 1 \mathrm{a}^{+} \mathrm{pDCs}$. The expression profile of CD11c and CD1a of cultured CD34 ${ }^{+}$cells was assessed by flow cytometry (FCM) on days 7, 14 and 21 of incubation. The R1 gate was set on viable cells (negative for 7AAD). FCM data show the R1-gated events. (a-c) FCM data of cells initially cutured with GTS. (d-f) FCM data of cells initially cultured with GTF. (g-i) FCM data of cells initially cultured with GTSF. The percentages of cells in each quadrant are presented in the lower right corner. 
GTS
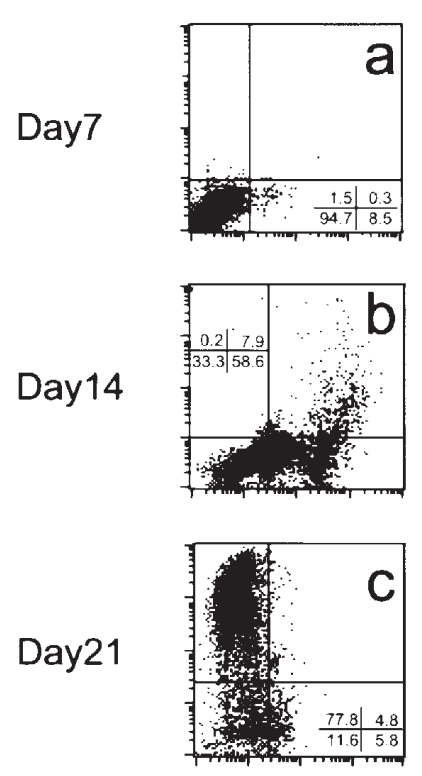

GTF
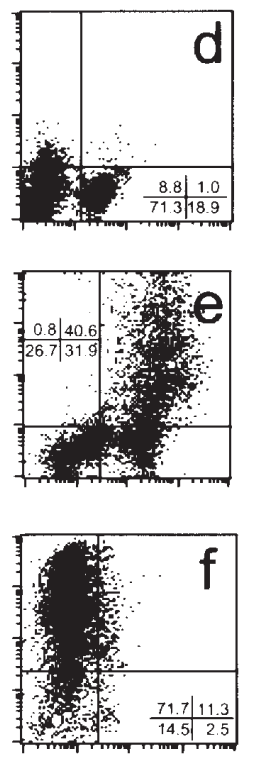

CD14 (FITC)
GTSF
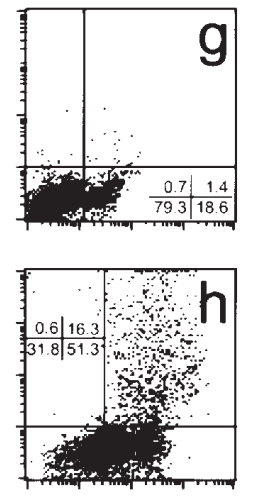

$\underset{\frac{1}{0}}{\frac{1}{0}}$

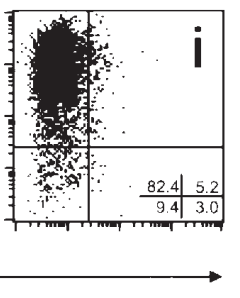

Figure 4. Differentiation of CD34+ cells to CD14+CD1a+ ${ }^{+}$DDCs. The expression profile of CD14 and CD1a of cultured CD34 ${ }^{+}$cells was assessed on days 7 , 14 and 21 of incubation. (a-c) FCM data of cells initially cutured with GTS. (d-f) FCM data of cells initially cultured with GTF. (g-i) FCM data of cells initially cultured with GTSF. The percentages of cells in each quadrant are presented in the lower right or upper left corner.

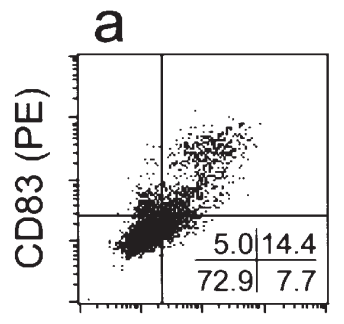

b

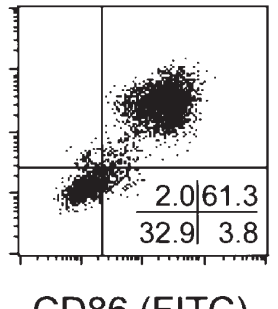

C

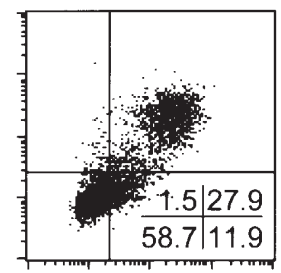

CD86 (FITC)

Figure 5. Expression of CD83 and CD86 on pDCs. Day-14 cells, which originated from CD34+ cells cultured with GTS (a), GTF (b) and GTSF (c), were further transferred to a terminal differentiation culture medium with G4TN and incubated for another 7 days. The R1 gate was set on viable cells. The data represent the R2-gated events, which were defined as high FSC/SSC fraction (DC gate). The percentages of cells in each quadrant are presented in the lower right corner.

pDCs, regardless of the initial cytokine combination used in the first step serum-containing culture. As well-documented in previous literature, neither CD11c, CD14 or CD1a, however, directly show the immunological function of DCs or pDCs. Therefore, it seems most important to clarify whether FL could contribute to the effective generation of functional and beneficial pDCs or not.

We compared the expression profiles of active antigenpresenting cell (APC) markers, CD83 and CD86, on culturegenerated DCs induced in the maturation cultures containing G4TN after the initial cultures with the designated combinations of cytokines, GTS, GTF, and GTSF. As shown in Fig. 5, the percentage of $\mathrm{CD} 83^{+} \mathrm{CD} 86^{+}$functional DCs, induced by G4TN after the initial cultures with GTF (Fig. 5b), was significantly higher than those induced after the other two initial combinations (Fig. 5a and c). These results suggest that FL can accelerate the differentiation of HPCs to pDCs, which are potentially ready to become APCs expressing surface costimulatory molecules.

We also estimated the functional properties of culturegenerated DCs by assessing their stimulating activity against proliferation of allogeneic T-lymphocytes. Representative data from three independent experiments are shown in Fig. 6. As clearly shown, DCs generated by GTF+G4TN more potently induced allogeneic $\mathrm{T}$-cell responses than those generated by GTS+G4TN or GTSF+G4TN. These results again illustrate that FL did advantageously induce the differentiation of HPCs to pDCs, which are ready to fully function as APCs in T-cellmediated immune responses.

\section{Discussion}

DCs are known as the professional APCs (6-8). Namely, they play an important role of capturing and processing antigen 


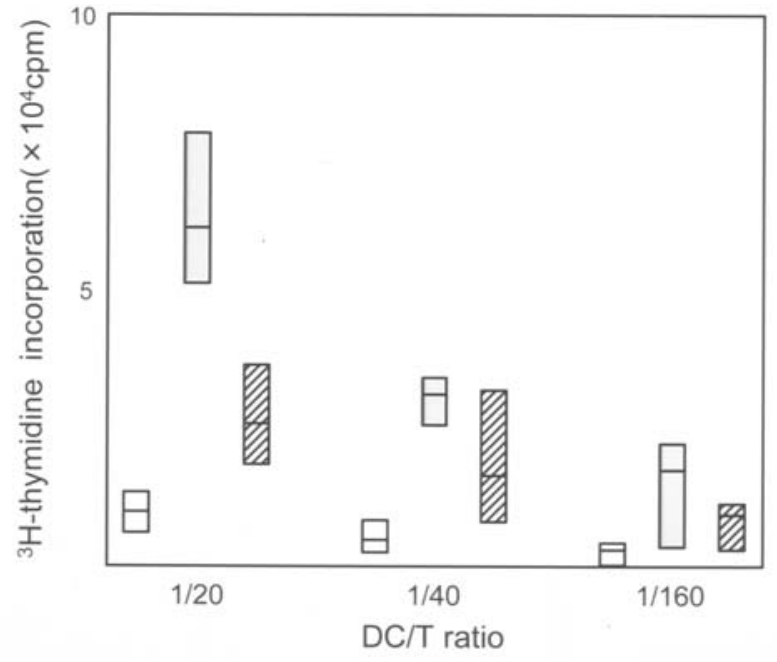

Figure 6. Proliferative response of allogeneic T-lymphocytes stimulated by culture-generated DCs. Day-21 cells, which were incubated with G4TN from day 14 , were irradiated at $250 \mathrm{cGy}$. Various numbers of these cells (stimulatorto-responder ratios are 1:20, 1:40, and 1:160) were incubated with HLAmismatched responder T-cells at $1 \times 10^{5} /$ well. The cells were harvested on day 5 after 8-12 h of exposure to $\left[{ }^{3} \mathrm{H}\right]$-thymidine. Open, gray and shaded columns respectively show data of DCs generated in initial 14-day cultures with GTS, GTF and GTSF. Horizontal bars represent the respective median values.

and presenting it to naïve helper T-cells to initiate the immune responses, including cytotoxic $\mathrm{T}$ lymphocyte (CTL) induction (5-7). Based on these findings, many doctors try to develop DC-based cancer immunotherapy (31).

Since G-CSF mobilizes monocytes as well as HPCs/HSCs in PB (34), many investigators used leukapheresis products to generate DCs for cancer immunotherapy $(33,35)$. However, recent studies have suggested that monocytes mobilized by G-CSF have a T helper (Th)-2 type cytokine production profile (36). In fact, G-CSF was reported to suppress the production of IL-12 and TNF $\alpha(37,38)$. Furthermore, another study suggested that G-CSF mobilizes DC2, not DC1, which stimulate T cell response into Th-2 type $(36,39)$. Collectively, apheresis products obtained by G-CSF may not be useful as a cell source for DC-based cancer immunotherapy, because Th-1 type immune response is required for elimination of tumor cells. In this context, we have investigated if apheresis products mobilized by G-CSF could be used for cancer immunotherapy considering their cytokine production profiles and the immune responses elicited by DCs generated from monocytes obtained after G-CSF mobilization (40). As a result, consistent with a previous report (41), these generated DCs were phenotypically and functionally equivalent to DCs generated from control monocytes. In fact, we have demonstrated that peptide-pulsed DCs generated in this manner could elicit optimal cytotoxic T-cell responses in some patients in a clinical study for cancer immunotherapy on patients bearing CEA-expressing solid cancer (42). On the other hand, we also previously demonstrated that a substantial number of $\mathrm{CD} 34^{+}$cells were mobilized in the peripheral blood and thus proposed the potential use of these G-CSF-mobilized CD34+ cells as a cell source for the expansion of pDCs in vitro (40). In the present study, we tried to address this possibility and also assessed their further use in the more efficient production of mature DCs for future cancer immunotherapy.
The ex vivo expansion and differentiation of myeloid DCs from $\mathrm{PB}$-derived $\mathrm{CD} 34^{+} \mathrm{HPC}$ require a combination of various cytokines, as previously reported $(24,25,43)$. It is well documented that there are three types of cytokine-generated DCs, including two types of myeloid DCs, such as CD14+ blood monocyte-derived DCs and CD $34^{+}$HPC-derived DCs, and CD11c-negative lymphoid DCs (44). Interestingly, CD34+ HPCs can give rise to any or all types of these DCs under the influence of particular cytokines in vitro. Among them, GM-CSF and IL-3 are the key cytokines to generate myeloid and lymphoid DCs, respectively (44). TNF $\alpha$, IL-4, transforming growth factor $\beta, \mathrm{IL}-10$, and vascular endothelial growth factor support or suppress the maturation/differentiation of these DCs (44). On the other hand, it was reported that SCF and FL, which are known to be early-acting cytokines (32), could support pDC expansion $(24,25)$. SCF stimulates DC formation from human $\mathrm{BM}$ - and $\mathrm{CB}$-derived $\mathrm{CD} 34^{+}$cells in combination with GM-CSF and TNF $\alpha$ without affecting DC differentiation $(31,45)$. FL also increases the production of DCs from BMderived $\mathrm{CD}_{3} 4^{+}$cells in combination with GM-CSF+IL-4 $+\mathrm{TNF} \alpha(46,47)$. This enhanced DC production is similar to the observed effects of SCF. However, as with SCF, FL does not affect the differentiation of DCs, but rather enhances the proliferation $(46,47)$. From another point of view, FL differs somewhat from SCF when used singly in vivo; however, it can increase both myeloid and lymphoid DCs (48). Preclinical human trials indicate a similar increase in circulating DCs, however, the precise mechanisms of action of these two cytokines remains unclear. In addition, FL has been reported to induce DC differentiation in vivo (46). However, precisely how the FL acts on CD34+ HPCs and/or pDCs thus inducing them to generate mature DCs remains to be elucidated. It was therefore considered to be necessary to truly understand the basic mechanisms of actions of FL on these DC precursor cells, in order to clarify the role of FL in vivo and to develop more effective anti-cancer immunotherapy in the near future.

In this context, we herein focused on the precise effects of FL on the process of DC maturation of human PB-derived CD $34^{+}$HPCs. Our data clearly demonstrated that FL has more potent and specific actions on human DC development, compared to SCF, another early-acting cytokine. Of note was that FL, in combination with GM-CSF plus TPO, induced a dramatic effect on the ex vivo expansion of CFU-DCs (Fig. 2). The addition of SCF did not show any additive effects. Moreover, this GTF combination accelerated the maturation of $\mathrm{CD} 34^{+} \mathrm{HPCs}$ to $\mathrm{CD} 14^{+} \mathrm{CD} 11 \mathrm{c}^{+} \mathrm{CD} 1 \mathrm{a}^{+} \mathrm{pDCs}$, as shown in Figs. 3 and 4. Because the expression of CD14 on CD34+ cells was first seen on day 7 in cultures containing GTF (but not GTS), a substantial proportion of DCs developing from CD34+ ${ }^{+}$HPCs do so via CD14+ bipotential intermediates $(41,45)$ (Figs. 3 and 4). These pDCs could then mature into CD14 CD $11 \mathrm{c}^{+} \mathrm{CD} 1 \mathrm{a}^{+} \mathrm{DCs}$ in the presence of GM-CSF, IL-4, and $\mathrm{TNF} \alpha$. These mature DCs express co-stimulatory molecules, such as CD83 and CD86 (Fig. 5). Importantly, these GTFgenerated mature DCs induce the most potent allogeneic T-cell responses in MLR in comparison to those of GTS and GTSF (Fig. 6). Both FL and SCF can expand pDCs as previously reported $(24,25)$. However, our results indicate for the first time that in comparison to SCF, FL acts differently on CD $34^{+}$HPCs, where it induced the proliferation/differentiation 
of G-CSF-mobilized PB-derived CD34+ cells to pDCs in the presence of GM-CSF and TPO.

In conclusion, our present study clearly demonstrated that a combination of GTF could efficiently expand CFU-DCs and generate functional mature DCs in vitro. Therefore, it is possible to develop a more efficient DC-based cancer immunotherapy using this specific cytokine combination, $\mathrm{GM}-\mathrm{CSF}+\mathrm{TPO}+\mathrm{FL}$ in vitro in the near future.

\section{Acknowledgements}

The authors are grateful to Dr Kaori Okugawa for her kind support. The authors also thank Kirin Brewery Co. Ltd. (Tokyo, Japan) and Ono Pharmaceutical Co. Ltd. (Osaka, Japan) for providing the various growth factors used in this study. This study was supported by Grants-in-Aid for Scientific Research on Priority Areas (grant no. 15039227) and for Scientific Research C (grant no. 15591015) from the Ministry of Education, Science and Culture of Japan, and grants from Haiteku Research Center of the Ministry of Education, the Science Frontier Program of the Ministry of Education, the Japan Leukemia Research Foundation, and the Mitsubishi Pharma Research Foundation.

\section{References}

1. Miyani H, Dragowska W and Lansdorp PM: Lineage commitment of human hemopoiesis involves asymmetric cell division of multipotent progenitors and does not appear to be influenced by cytokines. J Cell Physiol 157: 579-586, 1993.

2. Zipori D: The renewal and differentiation of hemopoietic stem cells. FASEB J 6: 2691-2697, 1992

3. Nutt SL, Thevenin C and Busslinger M: Essential functions of Pax-5 (BSAP) in pro-B cell development. Immunobiology 198: 227-235, 1997.

4. Metcalf D, Elliot MJ and Nicola NA: The excess numbers of peritoneal macrophages in granulocyte-macrophage colonystimulating factor transgenic mice are generated by local proliferation. J Exp Med 175: 877-884, 1992.

5. Steinmann RM: The dendritic cell system and its role in immunogenicity. Ann Rev Immunol 9: 271-296, 1991.

6. Cella M, Sallusto F and Lanzavecchia A: Origin, maturation and antigen presenting function of dendritic cells. Curr Opin Immunol 9: 10-16, 1997.

7. Banchereau J and Steinmann RM: Dendritic cells and the control of immunity. Nature 392: 245-252, 1998.

8. Salluso F and Lanzavecchia A: Mobilizing dendritic cells for tolerance, priming, and chronic inflammation. J Exp Med 189: 611-614, 1999.

9. Ardavin C, Wu L, Li CL and Shortman K: Thymic dendritic cells and $\mathrm{T}$ cells develop simultaneously in the thymus from a common precursor population. Nature 362: 761-763, 1993.

10. Shortman K, Vremec D, Corcoran LM, Georgopoulos K, Lucas K and Wu L: The linkage between T-cell and dendritic cell development in the mouse thymus. Immunol Rev 165: 39-46, 1998.

11. Inaba K, Inaba M, Romani $\mathrm{N}$, et al: Generation of large numbers of dendritic cells from mouse bone marrow cultures supplemented with granulocyte/macrophage colony-stimulating factor. J Exp Med 176: 1693-1702, 1992.

12. Inaba $\mathrm{K}$, Inaba M, Deguchi M, et al: Granulocytes, macrophages, and dendritic cells arise from a common major histocompatibility complex class II-negative progenitor in mouse bone marrow. Proc Natl Acad Sci USA 90: 3038-3042, 1993.

13. Young JW and Steinman RM: The hematopoietic development of dendritic cells: a distinct pathway for myeloid differentiation. Stem Cells 14: 3376-3387, 1996.

14. Small D, Levenstein M, Kim E, et al: STK-1, the human homolog of Flk-2/Flt-3, is selectively expressed in CD $34^{+}$human bone marrow cells and is involved in the proliferation of early progenitor/stem cells. Proc Natl Acad Sci USA 91: 459-463, 1994.
15. Mackarehtschian K, Hardin JD, Moore KA, Boast S, Goff SP and Lemischka IR: Targeted disruption of the flk $2 / \mathrm{flt} 3$ gene leads to deficiencies in primitive hematopoietic progenitors. Immunity 3: 147-161, 1995.

16. Matthews W, Jordan CT, Wiegand GW, Pardoll D and Lemischka IR: A receptor tyrosine kinase specific to hematopoietic stem and progenitor cell-enriched populations. Cell 65: 1143-1152, 1991 .

17. Brasel K, De Smedt T, Smith JL and Maliszewski CR: Generation of murine dendritic cells from flt3-ligand-supplemented bone marrow cultures. Blood 96: 3029-3039, 2000.

18. Gilliet M, Boonstra A, Paturel C, et al: The development of murine plasmacytoid dendritic cell precursors is differentially regulated by FLT3 ligand and granulocyte/macrophage colonystimulating factor. J Exp Med 195: 953-958, 2002.

19. Gabbianelli M, Pelosi E, Motesoro E, et al: Multi-level effects of flt 3 ligand on human hematopoiesis: expansion of putative stem cells and proliferation of granulomonocytic progenitors/monocytic precursors. Blood 86: 1661-1670, 1995.

20. Rusten LS, Lyman SD, Veiby OP and Jacobsen SEW: The FLT3 ligand is a direct and potent stimulator of the growth of primitive and committed human $\mathrm{CD} 34^{+}$bone marrow progenitor cells in vitro. Blood 87: 5016-5026, 1996.

21. Ohmizono Y, Sakabe H, Kimura T, et al: Thrombopoietin augments ex vivo expansion of human cord blood-derived hematopoietic progenitors in combination with stem cell factor and flt3 ligand. Leukemia 11: 524-530, 1997.

22. Sonoda Y, Kimura T, Sakabe H, et al: Human flt3 ligand acts on myeloid as well as multipotential progenitors derived from purified CD $34^{+}$blood progenitors expressing different levels of c-kit protein. Eur J Haematol 58: 257-264, 1997.

23. Sakabe H, Kimura T, Zeng ZZ, et al: Haematopoietic action of flt3 ligand on cord blood-derived CD34-positive cells expressing different levels of flt 3 or c-kit tyrosine kinase receptor: comparison with stem cell factor. Eur J Haematol 60: 297-306, 1998.

24. Bontkes HJ, De Gruijl TD, Schuurhuis GJ, Scheper RJ, Meijer CLM and Hooijberg E: Expansion of dendritic cell precursors from human $\mathrm{CD} 34^{+}$progenitor cells isolated from healthy donor blood; growth factor combination determines proliferation rate and functional outcome. J Leukoc Biol 72: 321-329, 2002.

25. Arrighi JF, Hauser C, Chapuis B, Zubler RH and Kindler V: Long-term culture of human $\mathrm{CD} 34^{+}$progenitors with FLT3ligand, thrombopoietin, and stem cell factor induces extensive amplification of a CD34-CD14- and a CD34-CD $14^{+}$dendritic cell precursor. Blood 93: 2244-2252, 1999.

26. Kimura T, Sakabe H, Tanimukai S, et al: Simultaneous activation of signals through gp130, c-kit, and interleukin-3 receptor promotes a trilineage blood cell production in the absence of terminally acting lineage-specific factors. Blood 90: 4767-4778, 1997.

27. Kimura T, Wang J, Minamiguchi H, et al: Signal through gp 130 activated by soluble interleukin (IL)-6 receptor (R) and IL-6 or IL-6R/IL-6 fusion protein enhances ex vivo expansion of human peripheral blood-derived hematopoietic progenitors. Stem Cells 18: 444-452, 2000.

28. Fujiki H, Kimura T, Minamiguchi H, et al: Role of human interleukin-9 as a megakaryocyte potentiator in culture. Exp Hematol 30: 1373-1380, 2002.

29. Kimura T, Minamiguchi H, Wang J, et al: Impaired stem cell function of $\mathrm{CD} 34^{+}$cells selected by two different immunomagnetic beads systems. Leukemia 18: 566-574, 2004.

30. Wang J, Kimura T, Asada R, et al: SCID-repopulating cell activity of human cord blood-derived CD34- cells assured by intra-bone marrow injection. Blood 101: 2924-2931, 2003.

31. Young JW, Szabolcs P and Moore MA: Identification of dendritic cell colony-forming units among normal human CD34 ${ }^{+}$ bone marrow progenitors that are expanded by c-kit-ligand and yield pure dendritic cell colonies in the presence of granulocyte/ macrophage colony-stimulating factor and tumor necrosis factor $\alpha$. J Exp Med 182: 1111-1119, 1995.

32. Lyman SD and Jacobsen SEW: c-kit ligand and Flt3 ligand: stem/progenitor cell factors with overlapping yet distinct activities. Blood 91: 1101-1134, 1998.

33. Banchereau $\mathrm{J}$ and Palucka AK: Dendritic cells as therapeutic vaccines against cancer. Nat Rev Immunol 5: 296-306, 2005.

34. Herrmann F, Brugger W, Kanz L and Mertelsmann R: In vivo biology and therapeutic potential of hematopoietic growth factors and circulating progenitor cells. Semin Oncol 19: 422-431, 1992. 
35. Reinhard G, Marten A, Kiske SM, Feil F, Bieber T and Schmidt-Wolf IG: Generation of dendritic cell-based vaccines for cancer therapy. Br J Cancer 86: 1529-1533, 2002.

36. Sloand EM, Kim S, Maciejewski JP, et al: Pharmacologic doses of granulocyte colony-stimulating factor affect cytokine production by lymphocytes in vitro and in vivo. Bood 95: 2269-2274, 2000.

37. Sivakumaran M, Vasconcelos ZF, Diamond HR, et al: Modulation of Th1/Th2 subsets by granulocyte-colony stimulating factor. Blood 97: 333-335, 2001.

38. Vasconcelos ZF, Diamond HR, Tabak DG, Barcinski MA and Bonomo A: Th1/Th2 lymphokine profile of $\mathrm{T}$ cells present in the blood of granulocyte-colony stimulating factor-treated stemcell donors: up or down modulation. Blood 95: 333-335, 2001

39. Arpinati M, Green CL, Heimfeld S, Heuser JE and Anasetti C: Granulocyte-colony stimulating factor mobilizes $\mathrm{T}$ helper 2inducing dendritic cells. Blood 95: 2484-2490, 2000.

40. Ueda Y, Itoh T, Fuji N, et al: Successful induction of clinically competent dendritic cells from granulocyte colony-stimulating factor-mobilized monocytes for cancer vaccine therapy. Cancer Immunol Immunother 8 (e-pub ahead of print), 2006.

41. Szabolcs P, Avigan D, Gezelter S, et al: Dendritic cells and macrophages can mature independently from a human bone marrow-derived, post-CFU intermediate. Blood 87: 4520-4530, 1996.
42. Ueda Y, Itoh T, Nukaya I, et al: Dendritic cell-based immunotherapy of cancer with carcinoembryonic antigen-derived, HLAA24-restricted CTL epitope: clinical outcomes of 18 cases with metastatic gastrointestinal or lung adenocarcinomas. Int J Oncol 24: 909-918, 2004.

43. Young JW: Dendritic cells: expansion and differentiation with hematopoietic growth factors. Curr Opin Hematol 6: 135-144, 1999.

44. Romani N, Gruner S, Brang D, et al: Proliferating dendritic cell progenitors in human blood. J Exp Med 180: 83-93, 1994.

45. Caux C, Vanbervliet B, Massacrier C, et al: $\mathrm{CD} 34^{+}$hematopoietic progenitors from human cord blood differentiate along two independent dendritic cell pathways in response to GMCSF+TNFa. J Exp Med 184: 695-706, 1996.

46. Lyman SD: Biologic effects and potential clinical application of FLT-3 ligand. Curr Opin Hematol 5: 192-196, 1998.

47. Szbolcs P, Moore MAS and Young JW: Expansion of immunostimulatory dendritic cells among the myeloid progeny of human $\mathrm{CD} 34^{+}$bone marrow precursors cultured with c-kit ligand, granulocyte-macrophage colony-stimulating factor, and tumor necrosis factor- $\alpha$. J Immunol 154: 5851-5861, 1995.

48. Morse MA, Nair S, Fernandez-Casal M, et al: Preoperative mobilization of circulating dendritic cells by Flt 3 ligand administration to patients with metastatic colon cancer. J Clin Oncol 18: 3383-3393, 2000. 